\title{
Linkage analysis in blepharophimosis-ptosis syndrome confirms localisation to $3 \mathrm{q} 21-24$
}

\author{
H S Harrar, S Jeffery, M A Patton
}

\begin{abstract}
Blepharophimosis-ptosis is an autosomal dominant disorder in which previous chromosome rearrangements have suggested a putative gene location on the long arm of chromosome 3 . This paper confirms the location at 3q21-24 with linkage studies in two large families. A lod score of 3.2 was found with D3S1237.
\end{abstract}

(f Med Genet 1995;32:774-777)

The blepharophimosis-ptosis syndrome (BPES) was first described in 1841 by Fredrich August von Ammon. ${ }^{1}$ It consists of blepharophimosis, ptosis, epicanthus inversus and some extraocular features such as learning difficulties and female infertility. The term blepharophimosis describes the reduction in the horizontal diameter of the palpebral fissure. This is associated with dysplasia of the eyelid owing to fibrosis and impairment of the laevator palpebrae superioris muscle. ${ }^{2}$ There may also be amblyopia and blockage of the lacrimal puncta. ${ }^{3}$ Surgical correction is available to improve the cosmetic appearance of the eyes.
Mild psychomotor retardation has been observed in some patients with one report giving a mean IQ score of $86 .{ }^{4}$ However most affected subjects have no significant learning difficulties. Infertility has been reported frequently in females but not in affected males. It has been suggested that there may be two subtypes depending on whether female infertility is present or not. ${ }^{5}$

The condition is an autosomal dominant trait. In 1991 Fukushima $e t a l^{6}$ published a case report of blepharophimosis sequence associated with a de novo balanced translocation $46, \mathrm{XY}, \mathrm{t}(3 ; 4)$ (q23;p15.2) and suggested that the locus might be assigned to $3 \mathrm{q} 23$. Following this Jewett $e t a l^{7}$ reported a further case associated with an interstitial deletion at $3 \mathrm{q} 22 .{ }^{7}$ The aim of our study was to confirm the putative location by linkage studies using two large families with BPES.

\section{Materials and methods}

The families were contacted and a full history and examination carried out on each member of the families. Inner canthal, outer canthal, and interpupillary distances were measured
Medical Genetics Unit, St George's Hospital Medical School, Cranmer Terrace, Condon SW17 0RE, UK H S Harrar

$S$ Jeffery

M A Patton

Correspondence to: Dr Patton.

Received 8 March 1995 Revised version accepted for publication 5 June 1995

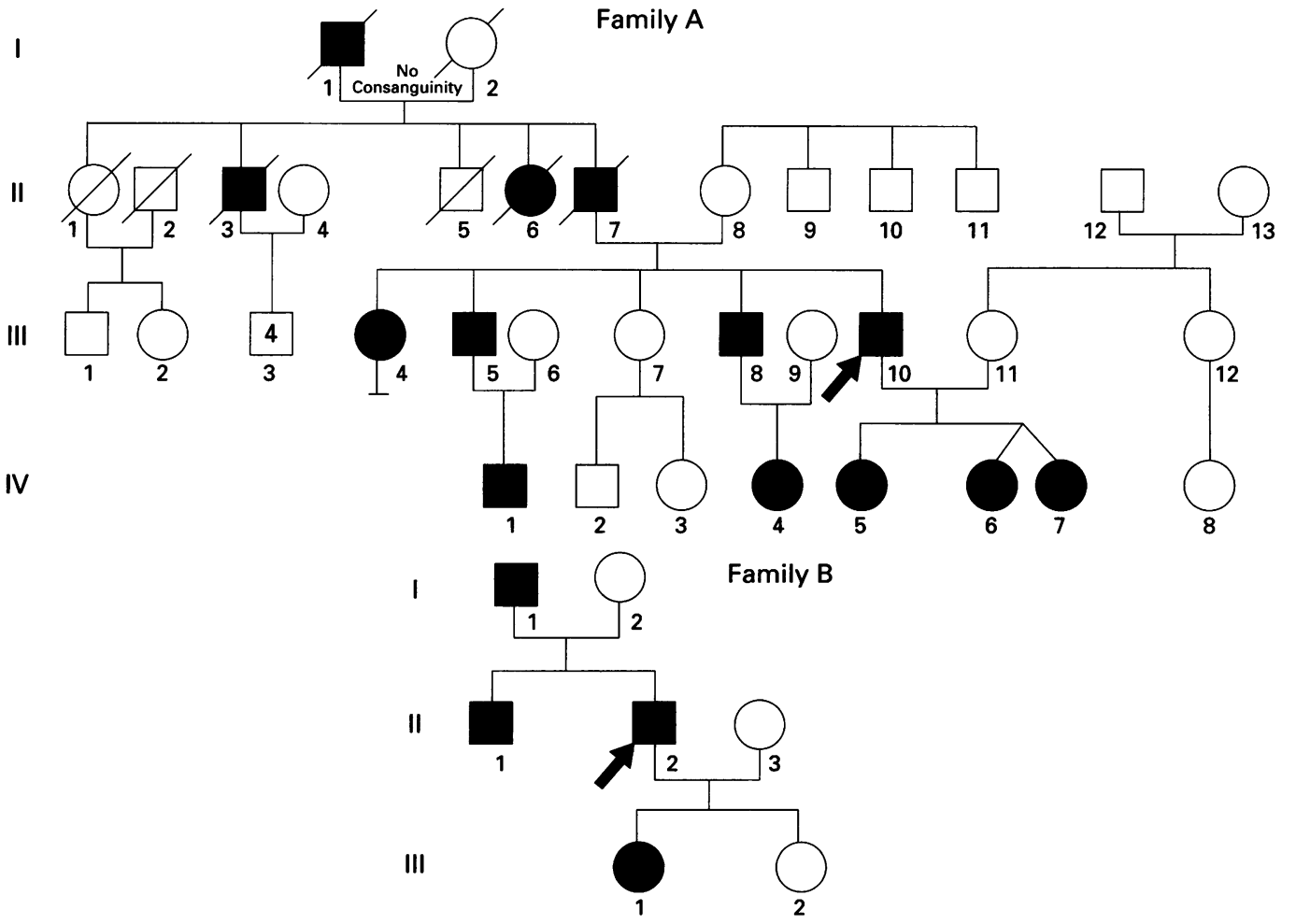

Figure 1 Pedigrees of family $A$ and family $B$ (twins $I V \cdot 6$ and $I V \cdot 7$ are dizygous). 
Lod scores for separate markers at different recombination fractions for both families

\begin{tabular}{llllllll}
\hline & 0 & 0.01 & 0.02 & 0.03 & 0.04 & 0.05 & 0.1 \\
\hline D3S1238 & 3.196 & 3.142 & 3.087 & 3.032 & 2.990 & 2.930 & 2.634 \\
D3S1309 & 1.204 & 1.182 & 1.160 & 1.138 & 1.116 & 1.093 & 0.915 \\
D3S196 & 2.878 & 2.829 & 2.779 & 2.729 & 2.679 & 2.628 & 2.367 \\
D3S1237 & 3.210 & 3.156 & 3.101 & 3.045 & 3.000 & 2.933 & 2.645 \\
\hline
\end{tabular}

using a metal rule and appropriate photographs were taken. A review of previous hospital records was carried out where there had been hospital investigations. Up to $20 \mathrm{ml}$ of blood in potassium EDTA was taken from affected and unaffected members of the families for DNA analysis. Loose buccal cells obtained by a sucrose mouthwash were used for DNA extraction from those who did not consent to venepuncture.

DNA was extracted from whole blood by the method described by Bertelson et al. ${ }^{8}$ Specific target sequences in the region of $3 q 2$ were amplified using the polymerase chain reaction. In view of the previous chromosome rearrangements the CA repeat primers D3S196, D3S1237, D3S1238, and D3S1309 were se-

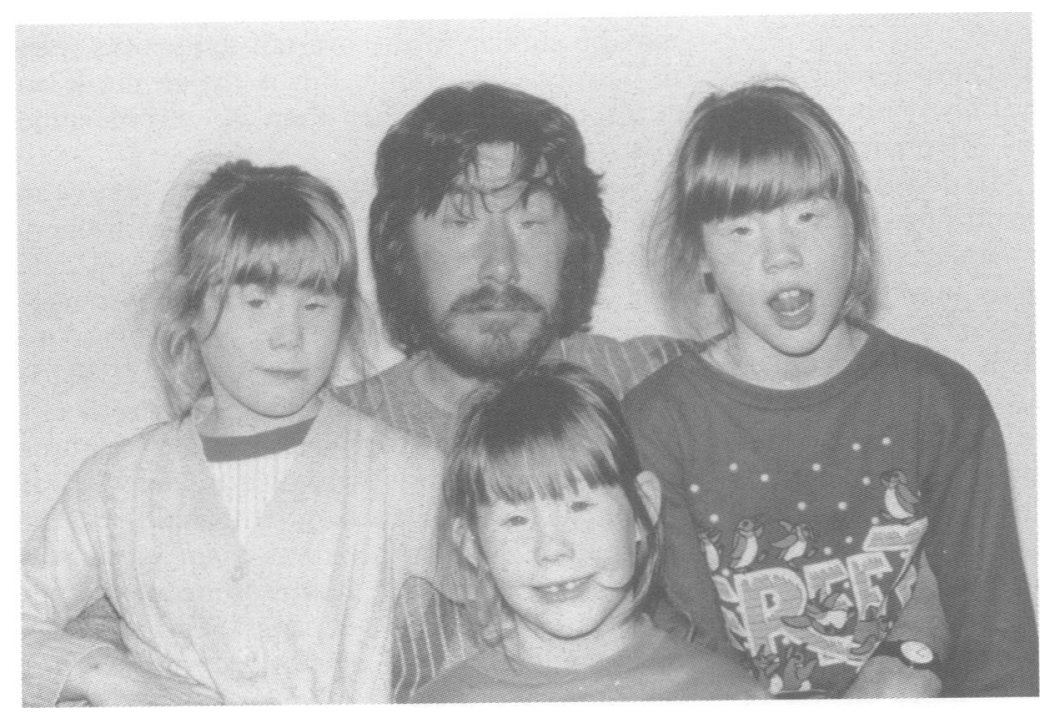

Figure 2 Affected father (III 10) and three affected daughters $(I V \cdot 5, I V \cdot 6, I V \cdot 7)$ in family $A$.

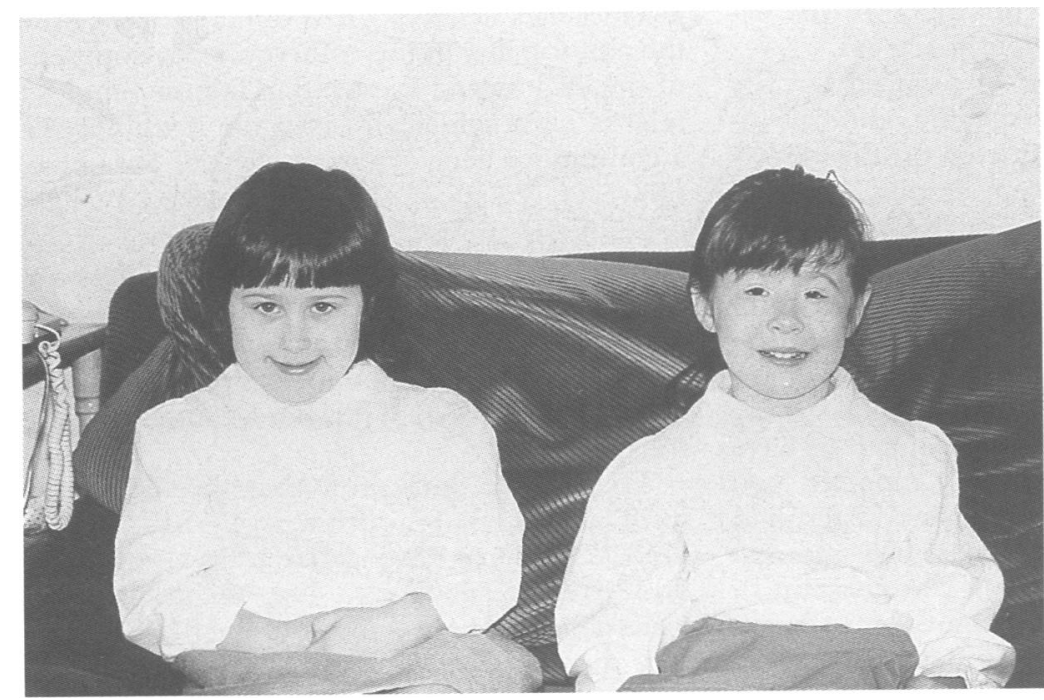

Figure 3 Affected and unaffected sisters in family B (III·1 and III·2).

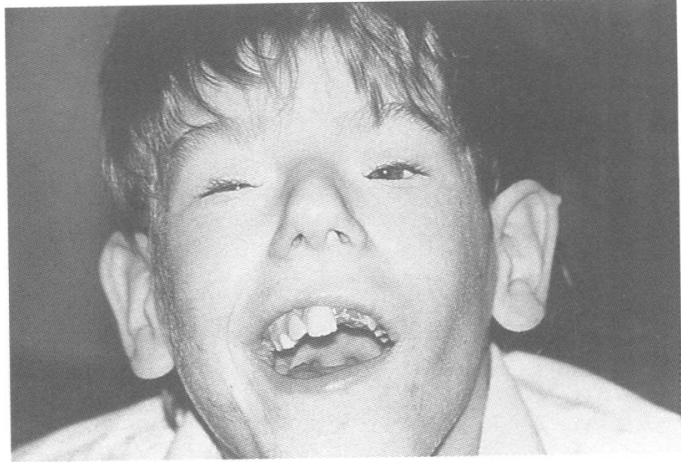

Figure $4 \quad I V \cdot 1$ in family $A$. This boy had learning difficulties, a single incisor, and dysgenesis of the corpus callosum.

lected and obtained from Research Genetics (table). Polymerase chain reaction (PCR) was performed as reported previously. ${ }^{\circ}$ Amplified products were separated using $10 \%$ PAGE, and visualised with silver stain. ${ }^{9}$ Lod scores were generated using the Mlink section of the LINKAGE package version $5.03 .{ }^{10}$ Pedigrees were entered into the LINKAGE program using the Megabase interface. ${ }^{11}$ The incidence of BPES was taken to be one in 10000 live births and complete penetrance was assumed. Allele frequencies were obtained from the genome database.

\section{Results}

There were nine affected subjects alive in family $A$ and four affected members in family B (fig 1). They all had the classical appearance of blepharophimosis-ptosis as illustrated in figs 2 , 3 , and 4 .

In family A two affected females, II 6 and III.4, had passed through their reproductive years and had reduced fertility. In III- 4 menarche was delayed at 17 years. Initially she had a normal menstrual pattern until 25 years, but after this the frequency of the menstrual cycles decreased. Extensive investigations including pelvic ultrasound, hormone studies, and pituitary function tests were undertaken. The ultrasound scans showed she had one ovary of reduced size. She was treated with Clomid (clomiphene) and Pergonal (menotrophin) without success. IV 4 had menarche at 12 years and at her present age of 16 years has regular periods and has not yet been investigated further. The remaining three affected females are prepubertal.

One affected member of family A (IV 1$)$ is a 9 year old boy with severe learning difficulties. He developed fits at the age of 10 months. CT brain scans have shown dysgenesis of the corpus callosum and enlarged lateral ventricles. $\mathrm{He}$ also has irregular teeth with a midline incisor (fig 4).

The results of the linkage analyses are shown in the table. The maximum lod score was 3.21 for D3S1237. Since no recombinations were observed, the recombination fraction $\theta=0$. The segregation of the haplotypes is shown in fig 5 . 

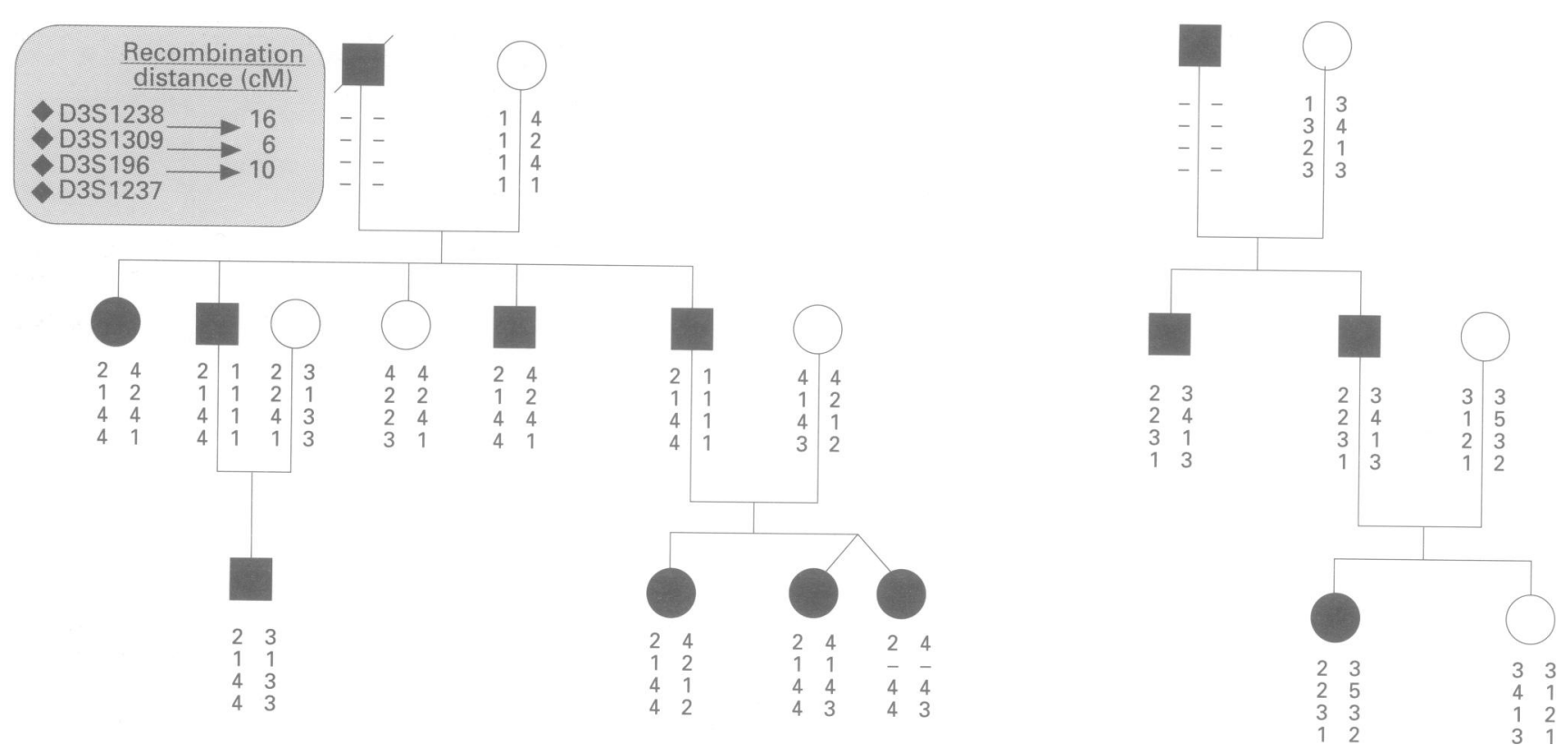

Figure 5 Segregation of haplotypes D3S1238, D3S1309, D3S196, D3S1237 in families A and B.

\section{Discussion}

This syndrome gives a very characteristic facial appearance, but it is not the only syndrome with blepharophimosis or ptosis. Blepharophimosis has been reported in the Marden-Walker syndrome $^{12}$ and the Ohdo syndrome. ${ }^{13}$ In these syndromes there are many associated features and developmental delay is more significant than in BPES. The degree of developmental delay that occurs in BPES is usually relatively mild and not associated with structural brain abnormalities. The patient reported here (family $A, I V \cdot 1)$ is unusual in having severe learning difficulties and a midline developmental defect manifest in dysgenesis of the corpus callosum and a single incisor. Clayton-Smith et al ${ }^{14} \mathrm{de}-$ scribed a boy with blepharophimosis, agenesis of the corpus callosum, and mental retardation, but the features in this case more closely resemble the Odho syndrome than BPES. Thus the association between BPES and midline cerebral abnormalities has not been observed previously, and suggests this may be the extreme end of the phenotypic spectrum.

There is no suggestion of reduced fertility in males, although no specific clinical investigation has been conducted on this. However, in females reduced fertility is well recognised and is a significant part of the clinical management of the disorder. In the families reported, most of the females have been prepubertal, but III. 4 in family A has been extensively investigated and appears to have primary ovarian failure. This finding is similar to published reports where investigations have been carried out. Smith et $a l^{15}$ reported two sisters with BPES in whom one sister had ovaries with a large number of primordial follicles on ovarian biopsy but was resistant to hormonal stimulation, and the other affected sister had no follicular development in the ovary and had a premature menopause. It appears the mechanism of reduced fertility in BPES may be similar to the ovarian dysgenesis seen in Turner's syndrome, but is the result of an autosomal gene rather than $\mathrm{X}$ chromosome loss.

Many single gene syndromes have first been mapped through their associations with chromosomal rearrangements. There is considerable evidence from chromosomal rearrangements that the gene for BPES is localised to the long arm of chromosome $3,{ }^{6716-21}$ at $3 \mathrm{q} 23$. However, it is interesting that Warburg et al ${ }^{1}$ reported a patient with many similar features to BPES in whom there was a deletion of 7q34. What is particularly interesting about this patient is that there was a single incisor, suggesting a partial holoprosencephaly sequence. In our family A patient IV 1 also has a single incisor and agenesis of the corpus callosum. We therefore feel that partial holoprosencephaly may be part of the BPES. It has already been suggested that BPES could be a contiguous gene syndrome with several adjacent genes deleted. ${ }^{14}$ It is difficult to see how the abnormality in the embryonic development of the eyelids and the ovarian failure could be related embryologically, and the possibility of a contiguous gene syndrome is very attractive. However, Vasalli et $a l^{2}$ have reported a single gene in the mouse, which affects both eyelid development and ovarian function. The gene produces the betaB subunit for activin and inhibin. It is located on mouse chromosome 9 and, as the human homologous region is 2cenq13 rather than $3 \mathrm{q} 23$, it is not a candidate gene for BPES.

The linkage data show that the lod scores were above 3 for primers D3S1237 and D3S1238. They are located at 3q21-q22 and $3 q 22-q 24$ respectively. No recombinations were observed between any of the markers and the disorder. It is surprising that no recombinations were seen between D3S1237 and D3S1238 considering the distance between 
them is in the order of $32 \mathrm{cM}^{23}$ The lack of recombination makes fine mapping more difficult unless further families with this rare disorder are studied. From the linkage data presented the gene locus for BPES is likely to be $3 \mathrm{q} 22-\mathrm{q} 23$, which correlates well with the putative localisation from chromosome rearrangements. A very recent paper by Small et $a l^{24}$ has also shown linkage of blepharophimosis-ptosis syndrome to $3 \mathrm{q}$. These pedigrees do show recombination with the markers used and the locus is placed proximal to D3S1309. The authors suggest that this places the BPES gene locus at 3q22-23, but D3S1309 maps to $3 \mathrm{q} 21^{23}$ and the most likely location for the BPES gene is given as near the RHO/ACPP markers at the proximal side of band $3 q_{13} .^{23}$ Although there are some discrepancies between the cytogenetic and genetic maps, this does not tie in with the most recent suggested cytogenetic location of the BPES gene. Further analysis of families with this syndrome, especially with more proximal markers, will improve the localisation.

We would like to thank Dr Caroline Berry for her help in contacting members of family $A$ and the families for their cooperation. Mr Harrar undertook this project for a BSc thesis.

1 Von Ammon FA. Klinisch Darstellung der Krankheiten und Bildungsfehler des Menschilichen Auges, der Augenglides und der Thranewerkzeuge. Berlin: G Reimers, 1841

2 Hughs WL. Surgical treatment of congenital palpebral phimosis. Arch Ophthalmol 1955;54:586-90.

3 Beaconsfield M, Walker JW, Collin JRO. Visual development in the blepharophimosis syndrome. Br $\mathcal{f}$ Ophthalmol 1991; 75:746-8.

4 Sacez R, Francfort J, Juif JG, de Grouchy J. Le blepharophimosis compliqué familial. Etude de membres de la famille Blepharophimosis. Ann Pediatr (Paris) 1963;10: 493-501.

5 Zlotogora J, Sagi M, Cohen T. The blepharophimosis, ptosis, epicanthus inversus syndrome: delineation of two types. Am ₹ Hum Genet 1983;35:1020-7.

6 Fukushima Y, Wakui K, Nishida T, Ueoka Y. Blepharophimosis sequence and a de novo balanced transpharophimosis sequence and a de novo balanced translocation $(46, \mathrm{XYt}(3 ; 4)$ (q23;p15.2): possible assignm
the trait to 3q23. Am $\mathcal{7}$ Med Genet 1991;40:485-7.

7 Jewett T, Nagesh Rao P, Grey Weaver R, Stewert W, Thomas IT, Pettenati MJ. Blepharophimosis, ptosis, epicanthus inversus syndrome (BPES) association with interstitial deletion of band 3q22: review and gene assignment to the interface of band 3q22.3 and 3q23. Am F Med Genet 1993; interface of band

8 Bertelson CJ, Pogo AO, Chaudhuri A, et al. Localisation Bertelson CJ, Pogo AO, Chaudhuri A, et al. Localisation
of the McLeod locus (XK) within Xp21 by deletion anaof the McLeod locus(XK) within Xp21
lysis. Am 7 Hum Genet 1988;42:703-11.

9 Jeffery S, Saggar-Mallik AK, Morgan S, MacGregor GA. A family with autosomal dominant polycystic kidney disease not linked to chromosome 16p13.3. Clin Genet 1993;44: 173-6.

10 Lathrop GM, Lalouel JM. Easy calculations of lod scores and genetic risks in small computers. Am $\mathcal{f}$ Hum Genet 1984;18:45-63.

11 Fenton I, Sandkuijl LA, Aldred MJ. A clinical DNA database capable of drawing pedigrees and communicating with the LINKAGE analysis package. Am ₹ Hum Genet 1990; 46(suppl):A56.

12 King CR, Magenis E. The Marden-Walker syndrome. $f$ Med Genet 1978;15:366-9.

13 Ohdo S, Madokoro H, Sonoda T, Hayakawa K. Mental retardation associated with congenital heart disease, blepharophimosis, and hypoplastic teeth. $\mathcal{f}$ Med Genet 1986; 23:242-4.

14 Clayton-Smith J, Krajewska-Walasek M, Fryer A, Donnai D. Ohdo-like blepharophimosis syndrome with distinctive facies, neonatal hypotonia, mental retardation and hypoplastic teeth. Clin Dysmorphol 1994;3:115-20.

15 Smith A, Fraser IS, Shearman RP, Russell P. Blepharophimosis plus ovarian failure: a likely candidate for a contiguous gene syndrome. $\mathcal{F}$ Med Genet 1989;26:434-8.

16 De Die-Smulders CEM, Engelen JJM, Donk JM, Fryns JP. Further evidence for the location of the BPES gene at 3q2. F Med Genet 1991;28:725.

17 De Almeida JCC, Llerena JC, Neto JBG, Jung M, Martins RR. Another example favouring the location of BPES at 3q2. F Med Genet 1993;30:86-8.

18 Fujita $H$, Meng J, Kawamura M, Tozuka N, Ishli F, Tanaka N. Boy with chromosome del (3) (q12-q23) and blepharophimosis syndrome. Am ₹ Med Genet 1992;44:434-6.

19 Ishikiriyama S, Goto M. Blepharophimosis sequence (BPES) and microcephaly in a girl with del (3) (q22.2q23): a putative gene responsible for microcephaly close q23): a putative gene responsible for microcephaly close
to the BPES gene? Am $\mathcal{F}$ Med Genet 1993;47:487-9.

20 Boccone L, Meloni A, Falchi AM, Usai V, Cao A. Blepharophimosis, ptosis, epicanthus inversus syndrome, a new case associated with de novo autosomal balanced translocation (46,XX,t(3;7) (q23;q32)). Am F Med Genet 1994;51:258-9.

21 Warburg M, Bugge M, Brøndum-Nielsen K. Cytogenetic findings indicate heterogeneity in patients with blepharophimosis, epicanthus inversus, and developmental delay. F Med Genet 1995;32:19-24

22 Vassalli A, Matzuk MM, Gardner HAR, Lee KF, Jaenisch R. Activin/inhibin BetaB subunit gene disruption leads to defects in eyelid development and female reproduction. Genes Dev 1994;8:414-27.

23 Cox Matise T, Perlin M, Chakravarti A. Automated construction of genetic linkage maps using an expert system (Multimap): a human genome linkage map. Nature Genet 1994;6:384-90.

24 Small KW, Stalvey M, Fisher L, et al. Blepharophimosis syndrome is linked to chromosome 3q. Hum Molec Genet 1995;4:443-8. 